\title{
Increased Risk of Asymptomatic Gallstones in Patients With Ulcerative Colitis
}

\author{
Jung Hoon $\mathrm{Ha}^{1}$, Young Sook Park ${ }^{1}$, Choon Sik Seon ${ }^{1}$, Byung Kwan Son ${ }^{1}$, Sang Bong Ahn ${ }^{1}$, Young Kwan Jo , \\ Seong Hwan Kim ${ }^{1}$, Yun Ju Jo ${ }^{1}$, Jung Hwan Kim², Jee Hye Han², Yoon Young Jung ${ }^{3}$, Sook Hee Chung ${ }^{4}$ \\ Department of Gastroenterology', Family Medicine, and Radiology ${ }^{3}$, Eulji General Hospital, Eulji University College of Medicine, Seoul, \\ Department of Gastroenterology,",Ajou University College of Medicine, Suwon, Korea
}

Background/Aims: The relationship between Crohn's disease and gallstones is established. However, the prevalence and risk factors for gallstones in patients with ulcerative colitis (UC) are not yet well understood. The aim of this study was to evaluate the prevalence and risk factors of gallstones in patients with UC. Methods: This study was a retrospective single center study. A total of 87 patients with UC and 261 healthy controls were enrolled. Age, sex, and body mass index were matched. To investigate risk factors, the extent of UC, duration of disease, number of hospital admissions, and number of steroid treatments in patients with UC were evaluated. Results: The prevalence of gallstones in patients with UC was 13.8\%, whereas that in healthy controls was only $3.1 \%(P<0.001)$. For patients with UC, patients $\geq 50$ years of age had a 3.6-times higher risk of gallstones compared to that in those $<50$ years of age, and the difference was statistically significant (odds ratio, 3.60; confidence interval, 1.0312.61) in univariate analysis. There were no statistically significant disease-related risk factors for gallstones in UC patients. Conclusions: This is the first study of gallstone prevalence in Korean UC patients. In this study, patients with UC had a higher prevalence of gallstones compared to that in well-matched healthy controls. Age seemed to be a possible risk factor, and more studies are needed. Further prospective, large-scale studies will be required to confirm the risk factors for gallstones in UC patients. (Intest Res 2015;13:122-127)

Key Words: Asymptomatic disease; Colitis, ulcerative; Gallstones; Prevalence; Risk factors

\section{INTRODUCTION}

The relationship between IBD and gallstones has been recognized since the late 1960s. ${ }^{1}$ However, the prevalence of gallstones in IBD patients and the risk factors for gallstones have not yet been established. The prevalence of gallstones in patients with $\mathrm{CD}$ has been investigated, and is known to range from 13 to $34 \%$, which is about two-fold higher than that in the general population. ${ }^{2-7}$ However, the findings re-

Received May 27, 2014. Revised October 24, 2014.

Accepted October 24, 2014.

Correspondence to Young Sook Park, Department of Internal Medicine, Eulji

General Hospital, Eulji University College of Medicine, 68 Hangeulbiseok-ro,

Nowon-gu, Seoul 139-711, Korea. Tel: +82-2-970-8207, Fax: +82-2-970-

8621,E-mail: pys1109@eulji.ac.kr

Financial support: None. Conflict of interest: None. ported for patients with UC are controversial. ${ }^{8}$

The prevalence of gallstones in the Korean general population ranges from 2 to $5 \% .^{9-11}$ Very few studies have been performed to investigate the prevalence of gallstones in patients with UC in Korea. Among the general population, the suggested risk factors for gallstones are female gender, old age, high body weight, and high-cholesterol diets. ${ }^{9,11}$ Some studies have suggested elevated BMI as a possible causal factor for gallstones in the general population. ${ }^{12}$

The aim of this study was to evaluate the prevalence of gallstones in patients with UC compared with a control population of similar age, sex, and BMI, and to identify risk factors for gallstones in UC patients.

\footnotetext{
๑ Copyright 2015. Korean Association for the Study of Intestinal Diseases. All rights reserved.

This is an Open Access article distributed under the terms of the Creative Commons Attribution Non-Commercial License (http://creativecommons.org/licenses/by-nc/3.0)

which permits unrestricted non-commercial use, distribution, and reproduction in any medium, provided the original work is properly cited.
} 


\section{METHODS}

\section{Study Population and Design}

The study was retrospective in design and involved a single center. We reviewed 124 patients with UC who visited the gastrointestinal department of Eulji General Hospital from 1996 to 2012. Among them, 87 patients with UC who had received either abdominal ultrasonography (US) or abdominal CT were enrolled. Patients with symptomatic gallstones and a history of cholecystectomy were excluded. Patients who had a history of either proctocolectomy, backwash ileitis into the terminal ileum, or primary sclerosing cholangitis were also excluded.

Clinical data of patients with UC including age, duration of disease, site and severity of disease, body weight and height, number of hospital admissions, and steroid administration were investigated. Patient age was defined as the age at the time of CT or US. Three-times the number of patients with UC ( $\mathrm{n}=261)$ who had received health-screening tests in the Department of Family Medicine from January 2011 to December 2012 were selected to serve as a control group. Age, sex, and BMI were matched with the UC group. Assessed risk factors included extent of UC, duration of disease, number of hospital admissions, and number of steroid treatments in patients with UC.

This study was performed with approval from the institutional review board of Eulji Hospital (EMCS 2014-07-009).

\section{Statistics}

Continuous variables were reported as means \pm SDs and analyzed using independent $t$-tests. Categorical variables were reported as counts and proportions, and analyzed using Pearson's Chi-square test or Fisher's exact test, as appropriate. A $P$-value $<0.05$ was considered statistically significant. Univariate and multivariate analysis was per-

Table 1. Demographic Characteristics of Patients With UC and Controls Matched for Age, Sex, and BMI

\begin{tabular}{lccc}
\hline Variables & Patients with UC & Healthy controls & $P$-value \\
\hline Age $(\mathrm{yr})$ & $42.66 \pm 15.02$ & $42.70 \pm 14.97$ & 0.982 \\
Sex & & & \\
$\quad$ Male & $43(49.43)$ & $129(49.43)$ & 0.902 \\
Female & $44(50.57)$ & $132(50.57)$ & 0.902 \\
BMl $\left(\mathrm{kg} / \mathrm{m}^{2}\right)$ & $21.52 \pm 3.08$ & $21.80 \pm 2.23$ & 0.547 \\
\hline
\end{tabular}

Values are presented as $n(\%)$ or mean \pm SD. formed using logistic regression analysis with the presence of gallstones as the dependent variable. Goodness of fit was checked using the Hosmer-Lemeshow test and residual analysis. Prevalence and ORs were calculated with 95\% CIs. A $P$-value $<0.05$ was considered statistically significant. Analysis was performed using SPSS version 17.0 (IBM Inc., Chicago, IL, USA).

\section{RESULTS}

\section{Prevalence of Gallstones in Patients With UC}

Eighty-seven patients with clinically and pathologically confirmed diagnoses of UC who also received abdominal CT or US were enrolled. An age-, sex-, and BMI-matched control group was selected from patients who visited the hospital for a health-screening test (Table 1). The number of cases of gallstones in patients with UC and the control group was 12 (6 males; prevalence of $13.8 \%$ ) and 8 ( 1 male; prevalence of $3.1 \%)$, respectively $(P<0.001$; Table 2$)$. CT or US was used for detecting gallstones in all cases. Twenty-one patients received abdominal US, 52 patients received abdominal CT, and 14 patients received both CT and US (Table 3) in the UC patients group. All of the control patients received US for gallstone detection.

\section{Risk Factors for Gallstones in Patients With UC}

Risk factors such as age, sex, BMI, number of hospital admissions, total length of hospital stay, number of total parenteral nutrition (TPN) treatments, and number of steroid treatments were analyzed (Table 4). Among the analyzed risk factors, age and BMI were found to be statistically significant in univariate analysis. For the patients with UC, the prevalence of gallstones for those $<50$ years of age and $\geq 50$ years of age was $8.47 \%(5 / 59)$ and $25.00 \%(7 / 28)$, respectively (Table 4). For patients with UC, those $\geq 50$ years of age had a 3.6-times higher risk of having gallstones compared to

Table 2. Prevalence of Gallstones Among Patients With UC and Controls Matched for Age, Sex, and BMI

\begin{tabular}{lcccc}
\hline \multicolumn{1}{c}{ Variables } & $\begin{array}{c}\text { UC } \\
\text { patients } \\
(\mathbf{n = 8 7})\end{array}$ & $\begin{array}{c}\text { Healthy } \\
\text { controls } \\
(\mathbf{n = 2 6 1 )}\end{array}$ & P-value & $\begin{array}{c}\text { OR } \\
(\mathbf{9 5} \% \mathrm{Cl})\end{array}$ \\
\hline With gallstones & $12(13.8)$ & $8(3.1)$ & $<0.001$ & $5.1(2.0-12.8)$ \\
$\begin{array}{l}\text { Without } \\
\quad \text { gallstones }\end{array}$ & $75(86.2)$ & $253(96.9)$ & $<0.001$ & $5.1(2.0-12.8)$ \\
\hline
\end{tabular}

Values are presented as $n(\%)$. 
Table 3. Liver Function Test Values and Gallstone-Detecting Modalities of UC Patients With and Without Gallstones

\begin{tabular}{lcccc}
\hline \multicolumn{1}{c}{ Variables } & UC overall patients $(\mathbf{n}=\mathbf{8 7})$ & With gallstones $(\mathbf{n}=\mathbf{1 2})$ & Without gallstones $(\mathbf{n}=\mathbf{7 5})$ & $P$-value \\
\hline AST (IU/L) & $22.5 \pm 7.9$ & $22.4 \pm 9.7$ & $22.5 \pm 7.7$ & 0.99 \\
ALT (IU/L) & $17.0 \pm 7.1$ & $17.0 \pm 7.2$ & $17.0 \pm 6.9$ & 1.00 \\
Total bilirubin $(\mathrm{mg} / \mathrm{dL})$ & $0.6 \pm 0.3$ & $0.6 \pm 0.2$ & $0.6 \pm 0.3$ & 0.75 \\
GGT (IU/L) & $39.4 \pm 60.9$ & $34.5 \pm 40.8$ & $40.2 \pm 63.7$ & 0.78 \\
US & 21 & 4 & 17 & \\
CT & 52 & 6 & 46 & 12 \\
US and CT & 14 & 2 & 12 & \\
\hline
\end{tabular}

Values are presented as mean \pm SD or $n$.

US, ultrasonography.

that in those $<50$ years of age, and the difference was statistically significant (OR, 3.60; 95\% CI, 1.03-12.61; $P=0.045$; Table 4) in univariate analysis, although it did not reach statistical significance in multivariate analysis.

Patients with UC and a BMI between 18.5 and 22.9 were found to have a decreased risk of gallstones (OR, 0.07; 95\% CI, 0.01-0.61; $P=0.016$; Table 4). However, in multivariate analysis, age, BMI, and sex did not reach statistical significance. All the other risk factors for gallstones analyzed, such as number of hospital admissions, total length of hospital stay, number of TPN treatments, extent of disease, and duration of disease did not reach statistical significance.

Liver function test values were also investigated. None of the values analyzed showed a significant difference between patients with and without gallstones (Table 3).

\section{DISCUSSION}

Gallstones are one of the most common medical conditions worldwide. The prevalence of gallstones varies with geography and ethnicity. In Western countries, the prevalence of gallstones among Caucasian adults is $10-15 \%,{ }^{13}$ and is less in Africans and Asians. ${ }^{14}$ The prevalence of gallstones in Asian countries ranges from 3 to $10 \%,{ }^{10}$ and in the Korean population, it ranges from 2 to $5 \%{ }^{9,15}$

Well-known risk factors for gallstones include age, sex, pregnancy, alcohol consumption, and high BMI..$^{10,12,16}$ Other suggested risk factors include rapid weight loss on low caloric diets or following bariatric surgery, ${ }^{17-21}$ and low physical activity. ${ }^{7,22-24}$

Many studies have investigated the prevalence and risks for gallstones associated with IBD. The prevalence of gallstones in CD patients ranges from 13 to $34 \%$, which is higher than that in the general population. ${ }^{1,2,6}$ This may be related to either terminal ileal disease or the post-ileal resection state, both of which deplete bile salts to subnormal concentrations in the duodenum during digestion. ${ }^{25,26}$ Bile salt malabsorption may cause biliary cholesterol supersaturation, and may also induce hepatic cycling of bilirubin. ${ }^{25,27}$ A prospective, case-controlled study showed that patients with CD were twice as likely to develop gallstones than well-matched IBDfree hospital controls. Age, site of CD at diagnosis, whether the patient underwent surgery, frequency of clinical recurrences, extent of ileal resection, number of hospitalizations, length of hospital stay, and a high number of TPN treatments were all independent variables associated with gallstones, the pathogenesis of which appears to be multifactorial. ${ }^{16}$ In contrast to $\mathrm{CD}$, the prevalence of gallstones in patients with UC remains controversial. In this study, the prevalence of gallstone in patients with UC was significantly higher than that in age-, sex-, and BMI-matched controls (13.8\% vs. $3.1 \%$; $P<0.001$; OR, 5.1; 95\% CI, 2.0-12.8; Table 2). We observed a more than four-times higher prevalence of gallstones in patients with UC than in controls. However, in this study the prevalence of gallstones in the control group was relatively low compared to the reported prevalence of gallstones in the general population of Korea (range, 2-5\%). This may be due to the fact that relatively lower BMI controls than the general population were included in the control group by selecting for age-, sex-, and BMI-matched patients. Mean BMI for the control group was $21.80 \pm 2.236$ (Table 1 ).

Lorusso et al. ${ }^{4}$ also reported that the prevalence of gallstones is higher in UC patients than in the general population. Their case-control study showed an increased risk of gallstones in both patients with $\mathrm{CD}(\mathrm{OR}, 3.6)$ and patients with UC $(\mathrm{OR}, 2.5)$. The risk was highest in patients with $\mathrm{CD}$ involving the distal ileum $(\mathrm{OR}, 4.5)$ and in patients with total UC extending to the cecum $(\mathrm{OR}, 3.3)$. The increased devel- 
Table 4. Distribution of Patients With UC According to the Prevalence of Gallstones and Selected Risk Factors

\begin{tabular}{|c|c|c|c|c|}
\hline \multirow{2}{*}{ Variables } & Univariate analysis & \multirow{2}{*}{$P$-value } & Multivariate analysis & \multirow{2}{*}{$P$-value } \\
\hline & OR $(95 \% \mathrm{Cl})$ & & OR $(95 \% \mathrm{Cl})$ & \\
\hline \multicolumn{5}{|l|}{ Age (yr) } \\
\hline$<50$ & 1.00 & & 1.00 & \\
\hline$\geq 50$ & $3.60(1.03-12.61)$ & 0.045 & $2.03(0.33-12.39)$ & 0.443 \\
\hline \multicolumn{5}{|l|}{ Sex } \\
\hline Male & 1.00 & & 1.00 & \\
\hline Female & $0.97(0.29-3.29)$ & 0.966 & $1.13(0.18-7.19)$ & 0.900 \\
\hline \multicolumn{5}{|l|}{$\mathrm{BMI}\left(\mathrm{kg} / \mathrm{m}^{2}\right)$} \\
\hline$<18.5$ & 1.00 & & 1.00 & \\
\hline $18.5-22.9$ & $0.07(0.01-0.61)$ & 0.016 & $0.91(0.10-0.84)$ & 0.091 \\
\hline$\geq 23$ & $0.97(0.29-3.29)$ & 0.093 & $0.18(0.18-1.82)$ & 0.180 \\
\hline \multicolumn{5}{|l|}{ No. of Admission } \\
\hline$<2$ & 1.00 & & & \\
\hline$\geq 2$ & $2.90(0.83-10.06)$ & 0.095 & & \\
\hline \multicolumn{5}{|l|}{ Total hospital day } \\
\hline$<2$ & 1.00 & & & \\
\hline $2-7$ & $0.14(0.02-1.25)$ & 0.079 & & \\
\hline$\geq 7$ & $0.51(0.13-1.95)$ & 0.324 & & \\
\hline \multicolumn{5}{|c|}{ TPN (No. of treatments) } \\
\hline 0 & 1.00 & & & \\
\hline 1 & $0.55(0.06-4.76)$ & 0.583 & & \\
\hline$\geq 2$ & $1.20(0.23-6.40)$ & 0.831 & & \\
\hline \multicolumn{5}{|c|}{ Steroid (No. of treatments) } \\
\hline $0-2$ & 1.00 & & & \\
\hline$\geq 3$ & $3.27(0.27-39.19)$ & 0.349 & & \\
\hline \multicolumn{5}{|l|}{ Extent of disease } \\
\hline Proctitis & 1.00 & & & \\
\hline Left colitis & $0.00(0.00-0.00)$ & 0.999 & & \\
\hline Extensive colitis & $0.63(0.18-2.20)$ & 0.469 & & \\
\hline \multicolumn{5}{|c|}{ Duration of disease (mo) } \\
\hline$<36$ & 1.00 & & & \\
\hline $36-96$ & $0.41(0.06-2.92)$ & 0.376 & & \\
\hline$\geq 96$ & $0.74(0.13-4.23)$ & 0.737 & & \\
\hline \multicolumn{5}{|l|}{ No. of relapse } \\
\hline No & 1.00 & & & \\
\hline $1-2$ & $0.37(0.07-2.08)$ & 0.262 & & \\
\hline$\geq 3$ & $0.74(0.51-8.35)$ & 0.306 & & \\
\hline
\end{tabular}

TPN, total parenteral nutrition. 
opment of gallstones in UC patients after ileostomy has been described. ${ }^{28,29}$

There are contradictory results concerning the prevalence of gallstones in UC patients. Bargiggia et al. ${ }^{7}$ reported that the prevalence of gallstones among CD patients was $11 \%$, which was higher than that in UC patients $(7.5 \%)$ and controls (5.5\%) $(P=0.016)$. The prevalence of gallstones was increased only in CD patients. Another case-control study showed that the incidence rates of gallstones was $14.35 / 1,000$ people per year in CD compared with 7.75 in matched controls $(P=0.012)$, and 7.48 in UC patients compared with 6.06 in matched-controls $(P=0.38){ }^{16}$ However, both of these studies were limited by the relatively small numbers of UC patients compared to patients with CD enrolled.

It was disappointing that we could not definitively identify the risk factors for gallstone in patients with UC in this study. An age of $\geq 50$ years was found to be a risk factor for gallstones in patients with UC in univariate analysis (OR, 3.60; 95\% CI, 1.03-12.61; $P=0.045$; Table 4). Furthermore, a BMI between 18.5 and 22.9 was associated with a decreased risk of gallstones in patients with UC in univariate analysis (OR, 0.07 ; 95\% CI, 0.01-0.61; $P=0.015$; Table 4 ). However, none of these factors reached statistical significance in multivariate analysis (Table 4). The prevalence of gallstones significantly increased with age from $8.47 \%$ in those $<50$ years of age to $25 \%$ in those $>50$ years of age (OR, 3.60; $95 \%$ CI, 1.03-12.61; $P=0.045$; Table 4). These findings are similar to those of Parente et al. ${ }^{16}$ who reported significantly increased (four-fold) risks of gallstones with increasing age in patients with $\mathrm{CD}$ (OR, 4.26). A similar trend was observed in patients with UC.

In our study, other expected risk factors, such as disease extent and steroid use, were not statistically significant. Kratzer et al. identified only age as a risk factor for gallstones, with prevalence increasing with age from $8 \%$ in those $<30$ years to $37 \%$ in those $\geq 51$ years. No disease-specific factors including duration and extent of disease and prior surgery were found to be associated with the prevalence of gallstones. ${ }^{30}$ However, Fraquelli et al. reported opposite results, suggesting that age, site of disease at diagnosis, and number and site of bowel resections were all independently associated with gallstone disease. ${ }^{31}$

There are reports that more than $20 \%$ of newly developed gallstones in Crohn's patients are symptomatic and require cholecystectomy. ${ }^{16}$ Furthermore, gallstones in IBD patients have been shown to be associated with an increased risk of post-cholecystectomy complications. UC is a chronic inflammatory disease, and it is therefore important for physicians to recognize and prevent complications, including gallstones. ${ }^{32}$

Histopathological characterization of cholecystectomy specimens was significantly more likely to reveal chronic cholecystitis and acute serositis in patients with UC than in controls. The association of acute serositis in patients with UC is an unusual finding, as full thickness inflammation is generally absent in the gastrointestinal tract of UC patients. Serositis may be related with increased post-operative infectious complications. ${ }^{33}$ These results suggest that physicians should pay attention to the management of gallstones in UC patients.

There are some limitations to the present study. First, it is retrospective in design with a relatively small study population, which limits the generalizations that can be made from the findings. Second, we could not differentiate cholesterol stones from pigment stones because all of the patients in our study were asymptomatic and diagnosed only by either CT or US scans. Although some studies have reported effective differentiation of stone composition by CT in vitro, many others have concluded that it is not possible to distinguish between types of gallstones using imaging modalities such as $\mathrm{CT}^{34,35}$

This is first study of gallstone prevalence in Korean UC patients. We concluded that patients with UC had a higher prevalence of gallstones compared with well-matched healthy controls. Age may be a risk factor for gallstones in patients with UC and controls. UC-related factors such as disease extent at diagnosis, frequency of clinical recurrences, number of hospital admissions, and steroid use were not statistically significant risk factors for gallstones in UC patients. A multicenter, prospective study will be needed to determine the overall prevalence of gallstones, and to define the high-risk subgroup of UC patients.

\section{REFERENCES}

1. Heaton KW, Read AE. Gall stones in patients with disorders of the terminal ileum and disturbed bile salt metabolism. Br Med J 1969;3:494-496

2. Baker AL, Kaplan MM, Norton RA, Patterson JF. Gallstones in inflammatory bowel disease. Am J Dig Dis 1974;19:109-112.

3. Whorwell PJ, Hawkins R, Dewbury K, Wright R. Ultrasound survey of gallstones and other hepatobiliary disorders in patients with Crohn's disease. Dig Dis Sci 1984;29:930-933.

4. Lorusso D, Leo S, Mossa A, Misciagna G, Guerra V. Cholelithiasis in inflammatory bowel disease. A case-control study. Dis Colon Rectum 1990;33:791-794. 
5. Kangas E, Lehmusto P, Matikainen M. Gallstones in Crohn's disease. Hepatogastroenterology 1990;37:83-84.

6. Lapidus A, Bangstad M, Astrom M, Muhrbeck O. The prevalence of gallstone disease in a defined cohort of patients with Crohn's disease. Am J Gastroenterol 1999;94:1261-1266.

7. Bargiggia S, Maconi G, Elli M, et al. Sonographic prevalence of liver steatosis and biliary tract stones in patients with inflammatory bowel disease: study of 511 subjects at a single center. J Clin Gastroenterol 2003;36:417-420.

8. Keulemans YC, Mok KS, Slors JF, et al. Concanavalin A-binding cholesterol crystallization inhibiting and promoting activity in bile from patients with Crohn's disease compared to patients with ulcerative colitis. J Hepatol 1999;31:685-691.

9. Chung YJ, Park YD, Lee HC, et al. Prevalence and risk factors of gallstones in a general health screened population. Korean J Med 2007;72:480-490.

10. Chang YR, Jang JY, Kwon W, et al. Changes in demographic features of gallstone disease: 30 years of surgically treated patients. Gut Liver 2013;7:719-724.

11. Lee JK, Rhee PL, Lee JH, et al. Prevalence and risk factors of gallstone in health screening people. Korean J Gastroenterol 1997;29:85-92.

12. Stender S, Nordestgaard BG, Tybjaerg-Hansen A. Elevated body mass index as a causal risk factor for symptomatic gallstone disease: a Mendelian randomization study. Hepatology 2013;58:2133-2141.

13. Kalser SC. National Institutes of Health consensus development conference statement on gallstones and laparoscopic cholecystectomy. Am J Surg 1993;165:390-396.

14. Shaffer EA. Gallstone disease: epidemiology of gallbladder stone disease. Best Pract Res Clin Gastroenterol 2006;20:981996.

15. Yi SY, Lee SK, Kim JW, et al. Clinical study on gallstone prevalence in general health screening people. Korean J Med 1994;47:352-358.

16. Parente F, Pastore L, Bargiggia S, et al. Incidence and risk factors for gallstones in patients with inflammatory bowel disease: a large case-control study. Hepatology 2007;45:1267-1274.

17. Liddle RA, Goldstein RB, Saxton J. Gallstone formation during weight-reduction dieting. Arch Intern Med 1989;149:1750-1753.

18. Shiffman ML, Sugerman HJ, Kellum JM, Brewer WH, Moore EW. Gallstone formation after rapid weight loss: a prospective study in patients undergoing gastric bypass surgery for treatment of morbid obesity. Am J Gastroenterol 1991;86:1000-1005.

19. Al-Jiffry BO, Shaffer EA, Saccone GT, Downey P, Kow L, Toouli J. Changes in gallbladder motility and gallstone formation following laparoscopic gastric banding for morbid obestity. Can J Gastroenterol 2003;17:169-174.
20. Weinsier RL, Wilson LJ, Lee J. Medically safe rate of weight loss for the treatment of obesity: a guideline based on risk of gallstone formation. Am J Med 1995;98:115-117.

21. Syngal S, Coakley EH, Willett WC, Byers T, Williamson DF, Colditz GA. Long-term weight patterns and risk for cholecystectomy in women. Ann Intern Med 1999;130:471-477.

22. Constantinescu T, Huwood Al Jabouri AK, Brãtucu E, Olteanu C, Toma M, Stoiculescu A. Gallstone disease in young population: incidence, complications, therapeutic approach. Chirurgia (Bucur) 2012;107:579-582.

23. Leitzmann MF, Giovannucci EL, Rimm EB, et al. The relation of physical activity to risk for symptomatic gallstone disease in men. Ann Intern Med 1998;128:417-425.

24. Leitzmann MF, Rimm EB, Willett WC, et al. Recreational physical activity and the risk of cholecystectomy in women. N Engl J Med 1999;341:777-784.

25. Heaton KW. Disturbances of bile acid metabolism in intestinal disease. Clin Gastroenterol 1977;6:69-89.

26. Dowling RH, Bell GD, White J. Lithogenic bile in patients with ileal dysfunction. Gut 1972;13:415-420.

27. Marks JW, Conley DR, Capretta TL, et al. Gallstone prevalence and biliary lipid composition in inflammatory bowel disease. Am J Dig Dis 1977;22:1097-1100.

28. Jones MR, Gregory D, Evans KT, Rhodes J. The prevalence of gallbladder disease in patients with ileostomy. Clin Radiol 1976;27:561-562.

29. Kurchin A, Ray JE, Bluth EI, et al. Cholelithiasis in ileostomy patients. Dis Colon Rectum 1984;27:585-588.

30. Kratzer W, Haenle MM, Mason RA, von Tirpitz C, Kaechele V. Prevalence of cholelithiasis in patients with chronic inflammatory bowel disease. World J Gastroenterol 2005;11:6170-6175.

31. Fraquelli M, Losco A, Visentin S, et al. Gallstone disease and related risk factors in patients with Crohn disease: analysis of 330 consecutive cases. Arch Intern Med 2001;161:2201-2204.

32. Choi CH, Kim YH, Kim YS, et al. Guidelines for the management of ulcerative colitis. Intest Res 2012;10:1-25.

33. Lin J, Shen B, Lee HJ, Goldblum JR. Histopathological characterization of cholecystectomy specimens in patients with inflammatory bowel disease. J Crohns Colitis 2012;6:895-899.

34. Sarva RP, Farivar S, Fromm H, Poller W. Study of the sensitivity and specificity of computerized tomography in the detection of calcified gallstones which appears radiolucent by conventional roentgenography. Gastrointest Radiol 1981;6:165-167.

35. Hickman MS, Schwesinger WH, Bova JD, Kurtin WE. Computed tomographic analysis of gallstones. An in vitro study. Arch Surg 1986;121:289-291. 